\title{
Preliminary study on the assessment of deadwood volume by the French national forest inventory
}

\author{
Rémi TEISSIER DU CROS*, Sandra LOPEZ \\ Inventaire forestier national, Échelon de Bordeaux, 62 rue de Laseppe, 33000 Bordeaux, France
}

(Received 18 October 2008; accepted 23 January 2009)

\begin{abstract}
Keywords:
deadwood /

line-intersect sampling /

fixed-area sampling /

national forest inventory
\end{abstract}

\begin{abstract}
- As the French national forest inventory does not currently monitor the lying compartment of the forest deadwood, the figures obtained on this topic are therefore partial. This study provides cost estimates and guidelines for assessing stumps, and standing and lying deadwood.

- Comparisons were made between a fixed-area sampling method and a line-intersect one. LIS was judged more time-efficient, especially in dense understorey. Computer simulations were performed in order to estimate the gain in precision with increasing transect lengths. The results showed a continuous improvement in precision associated with increases in transect length. The longest transect tested $(50 \mathrm{~m})$ still had a large coefficient of variation, suggesting that improvement in precision at the plot level could still be gained with longer transects.

- Therefore, from a practical standpoint in terms of fieldwork, we suggest that on a national scale lying deadwood should be measured by line-intersect sampling, whereas stumps, standing dead trees and snags can be monitored using standard fixed-area plots. To meet needs at the national level, we consider that local imprecision could be compensated for by the large number of plots measured each year.
\end{abstract}

Résumé - Étude préliminaire de l'évaluation du volume de bois mort à l'Inventaire forestier national français.

- L'inventaire forestier national français ne réalise pas l'inventaire du bois mort au sol, les résultats à ce sujet sont donc partiels. Cette étude donne des orientations en termes de coûts et de méthode pour l'échantillonnage des souches, arbres morts debout et le bois mort au sol.

- Les méthodes d'inventaire par placette à surface fixe et échantillonnage linéaire ont été comparées. L'échantillonnage linéaire a été jugé plus rapide surtout lorsque le sous-bois est dense. Des simulations ont été réalisées pour estimer le gain de précision avec l'augmentation de la longueur de transect. Les résultats ont montré une amélioration continue de la précision associée à l'augmentation de la longueur de transect. Le transect le plus long testé $(50 \mathrm{~m})$ a toujours un coefficient de variation élevé ; ce qui suggère que l'amélioration de la précision à l'échelle du point peu être obtenue avec un transect plus long.

- Du point de vue pratique au niveau du travail de terrain, nous suggérons qu'à l'échelle nationale le bois mort au sol soit mesuré par transect alors que les souches, arbres morts debout et chandelles soit mesurées avec la méthode standard des placettes fixes. Afin de satisfaire aux besoins de l'échelle nationale, nous avons considéré que l'imprécision locale peut être compensée par le nombre important de points mesurés chaque année.

\section{INTRODUCTION}

The French national forest inventory (NFI) is based on a systematic sampling grid that covers the national territory excluding overseas territories. Yearly, an average of 7000 nonpermanent plots are inventoried, making it possible to publish national results every year. This new sampling was launched in 2005 to meet the new needs of inventory data users: it is more flexible and allows the calculation of forest indicators required in national and international programs such as the global forest resource assessment of the Food and Agriculture Organization (FAO) and the sustainable forest indicators of the Ministerial Conference on the Protection of Forests in Europe (MCPFE). Among these indicators, deadwood is assumed to be linked to forest biodiversity. However, so far, the French NFI has not measured deadwood on a standard basis.

* Corresponding author: teissierducros@gmail.fr 
Only standing dead trees subjectively assumed to have died within the last 5 years are measured to estimate mortality. This value therefore is biased and underestimates the real deadwood volume within a plot, and fails to account for all other components such as lying deadwood and stumps. As no standard European method has been accepted in this aspect, published results are not comparable from one country to another. Each country has its own definitions and methods. A Cost action $\mathrm{E} 43$ on the harmonization of national forest inventories in Europe proposed guidelines for deadwood indicators.

For the deadwood assessment, a preliminary study was conducted to choose between various methods, and in regards to lying deadwood, to evaluate the impact of the choice of the diameter thresholds on the final volume estimations. The resulting method will need to be compatible with the fieldwork that is already being carried out all over France. Field crews ( 2 to 3 people) inventory an average of two plots per day; the deadwood assessment should not be too time-consuming or make it impossible to inventory the two plots in one day. It will also need to be accurate on a national or inter-regional scale using one annual plot fraction. This generated a great number of constraints when building a protocol.

Aboveground deadwood, also called coarse woody debris, may include whole fallen trees, fallen branches, pieces of fragmented wood, stumps and standing dead trees (Woldendorp et al., 2004). This study focuses on forest aboveground deadwood with floor coarse woody debris, referred to as CWD, snags for dead standing trees, and broken trees and stumps. There is little agreement in the literature for minimum diameters for CWD (Feller, 2003). A distinction is commonly made between CWD and fine woody debris (FWD). There are no clearly defined criteria for separating these woody debris classes; this study considers CWD and FWD to be a whole group, called CWD for convenience, and examines the effect of the choice of a minimum diameter. As the Swiss NFI points out, the minimum diameter and other applied limits must be chosen with care (Böhl, 2007). Cost action E43 advises European NFIs to evaluate deadwood indicators by the volume of standing and lying deadwood by region, by decay class and species or group of species, and the ratio of living volume. The main variables of interest in this paper for deadwood are, firstly, volume and secondly, but in less detail, biomass through decay classes.

Deadwood is an important component of forest ecosystems in that it provides habitats or micro-habitats, nutrients for saproxylic species, fertility for the soil, recycling of nutrients, trophic substrate, soil texturing and structuring, and temporary carbon stock (Stevens, 1997). In Scandinavia, Stokland pointed out that about $25 \%$ of the total forest species are woodinhabiting species (Stokland et al., 2004).

Forest deadwood is a recognized indicator of forest biodiversity as it helps describe the quality and status of habitats and structural diversity within a forest. Deadwood volume (indicator 4.5) is required by criterion 4 of the MCPFE protocol. In criterion 1 , for the carbon stock indicator (indicator 1.4), deadwood biomass contributes in part to the aboveground carbon stock (MCPFE, 2003).
A variety of methodologies are available, including lineintersect sampling (LIS) (Kaiser, 1983; Van Wagner, 1968; Warren and Olsen, 1964), fixed-area sampling (FAS) (Harmon and Sexton, 1996), transect relascope sampling (Ståhl, 1997) and point relascope sampling (Gove et al., 1999). Lineintersect, transect relascope, and point relascope sampling are all probability-proportional-to-size sampling methods. FAS methods for CWD are based on the frequency of occurrence of individual pieces of CWD (Jordan et al., 2004).

In this paper LIS is tested for CWD and FAS is tested for stumps, snags and CWD.

In practice, for FAS, a plot of known area is laid out in the forest and each piece that lies within (or partially within) the plot is tallied and parameters of interest are recorded. Estimates of per-unit area values can be obtained by multiplying any parameter by the reciprocal of the plot size (Jordan et al., 2004).

LIS is performed by establishing a sample line in the forest and tallying or recording parameters of interest for each piece of CWD that intersects the sample line (Jordan et al., 2004).

Woldendorp (Woldendorp et al., 2004) experimented with FAS in comparison with LIS. FAS on a $50 \mathrm{~m} \times 50 \mathrm{~m}$ square plot has a lower coefficient of variation than an $80 \mathrm{~m}$ LIS. Inventorying an 80-m LIS or more is much more efficient than a $2500 \mathrm{~m}^{2}$ plot. FAS provides higher precision with lower efficiency than LIS. FAS is appropriate when there is little CWD (McKenzie et al., 2000).

As the frequency of CWD generally increases with decreasing diameter size, some CWD methodologies determine the length of a transect (or length of a transect section) to be sampled by a diameter of woody debris, particularly when fine woody debris is included (Delisle et al., 1988; Woodall and Williams, 2005). In these methods, transects are divided into sections, and measurements on these sections correspond to diameter size classes. This ensures that over-sampling does not occur for small wood pieces and that a sufficient number of the largest-sized pieces are sampled (Woldendorp et al., 2004).

Using the results of COST action E43 questionnaires on European NFIs, for other European countries' NFIs, snags are usually inventoried using FAS where surface area depends on the snag DBH class (Belgium, Switzerland, Spain, Lithuania, Sweden and the United Kingdom). CWD is mainly inventoried using FAS, but LIS is used in Switzerland and Slovakia. Almost every country has its own thresholds such as minimum diameter, ranging from $4 \mathrm{~cm}$ in Sweden to $20 \mathrm{~cm}$ in Germany. Minimum diameter can be different depending on the type of deadwood. For example, Austria has $5 \mathrm{~cm}$ for snags and $20 \mathrm{~cm}$ for CWD.

For the two European countries using LIS, the Swiss NFI assesses one 30-m transect divided into three directions with a minimum diameter of $5 \mathrm{~cm}$ for CWD and the Slovakian NFI assesses two 25.4-m transects with a minimum diameter of $7 \mathrm{~cm}$ for CWD.

In the United States, CWD and FWD are assessed using LIS on "Y"s overlaid on 4 subplots. FWD (two classes: 0.64$2.51 \mathrm{~cm}$ and $2.52-7.59 \mathrm{~cm}$ ) are tallied on shorter transects than CWD ( $\geq 7.60 \mathrm{~cm}$ ), respectively, $7.32,12.19$ and $87.78 \mathrm{~m}$ (Woodall and Williams, 2005). 


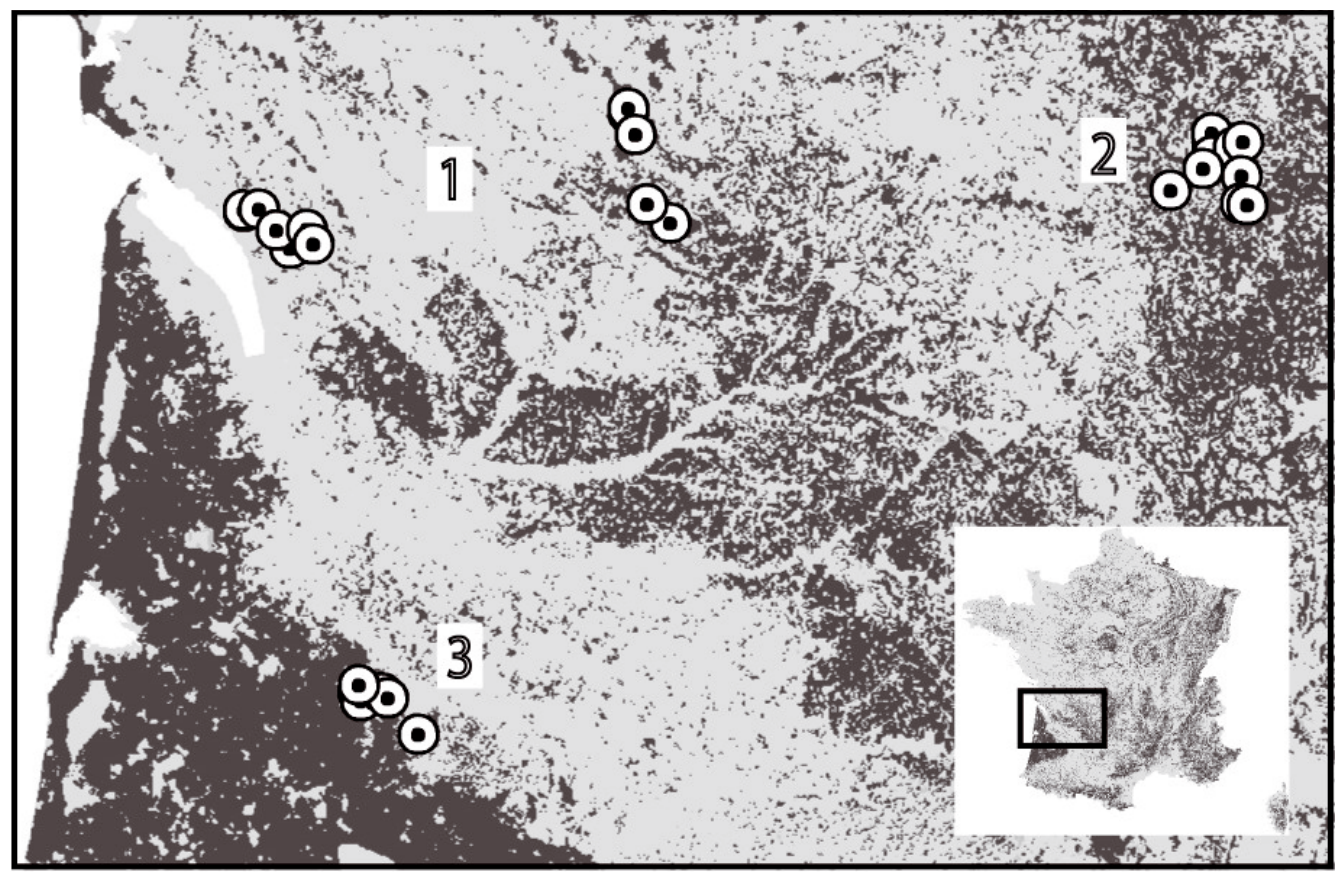

Figure 1. Location of the 31 plots in three groups overlaid on the forest map of the Southwest of France. Group 1 had a majority of coppice or coppice with reserves; group 2 had a majority of pure high forest or mixed forest and group 3 had a majority of high forest and coppice.

The Canadian design inspired our testing protocol in numerous points. Snags are assessed on FAS with living trees. Two 30-m line transects, perpendicular to each other, are used to measure CWD $(>7.5 \mathrm{~cm})$ and small woody debris $(>1.0 \mathrm{~cm}$ diameter $\leq 7.5 \mathrm{~cm}$ ). The first $10 \mathrm{~m}$ of each transect from the center of the plot are dedicated to CWD, the last $5 \mathrm{~m}$ are for both coarse and small woody debris. FWD under $1 \mathrm{~cm}$ are collected, oven-dried and weighed from four $56-\mathrm{cm}$-radius microplots.

In the discussion section, when appropriate, details of the protocol tested in this article will be compared with existing inventories.

CWD serves as critical habitats for a variety of flora and fauna. Flora use the microclimate of moisture, shade and nutrients provided by CWD to establish regeneration (Harmon et al., 1986).

CWD provides a wide range (stages, size classes and species) of habitats for fauna (Bull et al., 1997). For ecological aspects, recording decay classes gives an overview of these habitats. Furthermore, decay classes are necessary to convert the deadwood of woody debris into carbon stock via biomass. The common approach for obtaining biomass estimates of wood density is to convert volume into mass by using an estimate of wood density for various decay classes. Density varies considerably between tree species and between logs in various stages of decay (Caza, 1993). While numerous studies have been carried out in other countries, few data are available for French species. For the study, five decay classes were tested based on the description of sapwood and heartwood (Tab. I).

This paper discusses the results of a preliminary study that was intended to guide the French NFI in its choice of a method
Table I. Decay classes tested in the field recorded for each log or snag (Modified from Wadell, 2002).

\begin{tabular}{|c|c|}
\hline Decay class & Definition \\
\hline Absent & Intact wood \\
\hline Low & Sapwood partially decayed, heartwood intact \\
\hline Medium & $\begin{array}{l}\text { Sapwood decayed, can be pulled by hand, } \\
\text { heartwood intact }\end{array}$ \\
\hline High & $\begin{array}{l}\text { Sapwood totally rotten, heartwood rotten, log does } \\
\text { not support its weight, but shape remains }\end{array}$ \\
\hline Very high & $\begin{array}{l}\text { No structural integrity, no longer maintains } \\
\text { shape, soft }\end{array}$ \\
\hline
\end{tabular}

and thresholds to estimate the different compartments of deadwood in the national forests.

\section{MATERIALS AND METHODS}

\subsection{Study area}

A deadwood protocol for a NFI has to be applicable to all forest types that can be found in France, from high forest to coppice. The 31 plots assessed for the experiment were stratified as much as possible between the main French forest structures and compositions, respectively, divided into three classes: high forest, coppice with reserves and coppice for the structure, and broadleaved, coniferous and mixed for the composition. Plots were assessed in southwest France (Fig. 1), where a storm damaged the forest in 1999. The 31 plots can be divided into three groups. In group 1, there was a majority of coppice or coppice with reserves, coppice mainly constituted 
Table II. Plot distribution by estimated windthrow amount. Absent and low classes are the most represented type of windthrows in the sampling.

\begin{tabular}{lccccc}
\hline Windthrow amount & Absent & Low & Medium & High & Total \\
\hline Number of plots & 11 & 11 & 6 & 3 & 31 \\
\hline
\end{tabular}

of oak (Quercus robur, Quercus petraea), sweet chestnut (Castanea sativa) and European hornbeam (Carpinus betulus) and reserves with oaks (Quercus robur, Quercus petraea) and maritime pine (Pinus pinaster). The second group had a majority of pure high forest or mixed forest with, for broadleaved species, beech (Fagus sylvatica) and oaks (Quercus robur, Quercus petraea), and for coniferous, Scots pine (Pinus sylvestris), Douglas fir (Pseudotsuga menziesii), Norway spruce (Picea abies) and Japanese larch (Larix kaempferi) with coppice mainly constituted of oak and birch (Betula sp.). The last group included oak high forest and coppice with alder (Alnus glutinosa), hornbeam and Black locust (Robinia pseudoacacia).

A wide range of windthrow volume was assessed to test the protocol under various deadwood volume conditions (Tab. II). Damage maps helped us locate stands with various classes of damage. Age was not taken into account in the plot distribution due to the small number of plots.

\subsection{Protocol}

Our sampling protocol compares FAS and LIS for the lying deadwood. It is designed to enable resampling of data in order to multiply the sampling configuration with various transect lengths or different thresholds in minimum diameters of the CDW.

The protocol is based on NFI dendrometric plots: three concentric circles with radii of $6 \mathrm{~m}, 9 \mathrm{~m}$ and $15 \mathrm{~m}$, respectively. The 9-m-radius plot is used for FAS (stumps and lying deadwood). Snags are measured on the 6-, 9- and 15-m-radius dendrometric plots using NFI diameter classes for small, medium and large wood. For LIS of CWD, based on the $100 \mathrm{~m}$ recommended by the Good Practice Guidance for Land Use, Land-Use Change and Forestry (IPCC, 2003), two perpendicular 50-m lines intersected in the middle are overlaid on the plot. Each half-line is divided into four sections of $6 \mathrm{~m}, 3 \mathrm{~m}, 6 \mathrm{~m}$ and $10 \mathrm{~m}$ where the NFI concentric circles intersect them. The transect of each plot contain 16 sections having a defined length (Fig. 2). The frame is oriented randomly to avoid orientation bias when estimating CWD.

Stand on each plot is described using NFI forest types. Cover by structure and the level of windthrow damage is recorded. Tree species, when possible, or species groups (broadleaved or coniferous) and decay classes are assigned to every assessed deadwood piece. Each step of the measurement is timed: for FAS this includes the total operation by component and for LIS the installation of the transect and the measurement of the diameter by section.

FAS is used to assess stumps, snags and CWD. Stump assessment is carried out in the 9-m-radius plot. Mid-diameter and stump heights from the ground are recorded. Volume is calculated using formula (1). Snags are trees having an angle with the horizontal greater than $45^{\circ}$ (Wadell, 2002; Woodall and Williams, 2005); if smaller, snags are considered as CWD. They are assessed in the NFI dendrometric 6-, 9- and 15-m-radius plots, from a diameter of 7.5 to $22.5 \mathrm{~cm}$ excluded in the 6-m plot, from 22.5 to $37.5 \mathrm{~cm}$ excluded in the $9-\mathrm{m}$ plot and more than $37.5 \mathrm{~cm}$ in the $15-\mathrm{m}$ plot. Only DBH is recorded for whole standing trees. Volume is calculated using formula (2). For broken

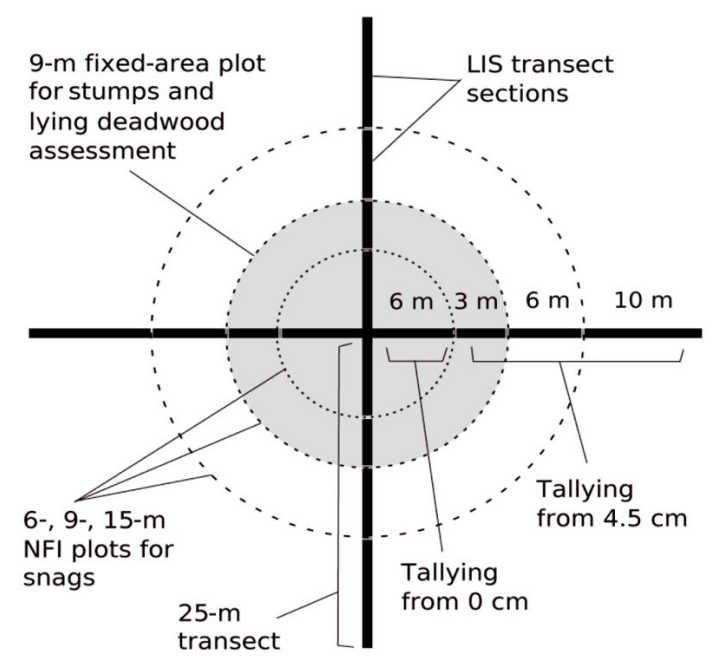

Figure 2. Test protocol for FAS and LIS with a 100-m transect overlaid on NFI dendrometric plots. Snags are assessed on the 6-, 9- and 15-m-radius NFI plots, Lying deadwood is assessed for fixed area sampling on the 9-m-radius plot and for LIS on the four 25-m transects. On the center 6-m transect sections CWD is tallied from $0 \mathrm{~cm}$; on the 3-, 6- and 10-m sections CWD is tallied from $4.5 \mathrm{~cm}$.

snags, in addition to DBH, the broken height is recorded and the volume is calculated using formula (3).

CWD is assessed on the 9-m-radius plot. If a piece crosses the limit of the circle, it is virtually cut there (Bruciamacchie, 2005) and only the volume within the circle is tallied. Length and mid-diameter are recorded for a minimum end diameter of $7 \mathrm{~cm}$. Volume is calculated using formula (4).

LIS is performed on two perpendicular 50-m lines (slopecorrected, horizontal length). Diameters of all CWD pieces are recorded at the point of intersection with the transect. If a piece is forked or intersects the transect many times, the diameter is recorded at each intersection. On the four central 6-m sections, the minimum diameter is $0.5 \mathrm{~cm}$, and for the rest it is $4.5 \mathrm{~cm}$. This is a way of comparing CWD volume with various minimum diameters and avoiding over-sampling on small diameters.

\subsection{Volume calculation}

Depending on the deadwood component, there are many ways of estimating volume.

A study (Filho et al., 2000) on various ways of calculating log volume showed that Huber's formula (1) is more accurate for all volumes and $\log$ lengths considered. This formula is widely used by inventories for snags and CWD. It is used in this study to calculate the volume of CWD and stumps on fixed-area plots. If a whole tree is measured, each time the diameter decreases more than $10 \%$ after a defect, the tree is divided into logs that are measured using Huber's formula until the minimum diameter is reached.

Huber's formula:

$$
V=\frac{L \pi d_{\mathrm{m}}^{2}}{4}
$$

$V=\mathrm{CWD}$ or stump volume,

$L=$ Length of the log or height of the stump,

$d_{\mathrm{m}}=$ mid-diameter of the log or the stump. 
Table III. Distribution of deadwood volume in cubic meters by component (snags, stumps and CWD) and by decay class using FAS. CWD pieces are the main components of deadwood followed by snags. Stumps represent a small volume. The medium decay class is the most frequent, followed by absent and high. CWD and snags are mostly in the medium decay class. Stumps are most represented in both medium and high decay classes.

\begin{tabular}{lccccc}
\hline Decay class & Snags & Stumps & CWD & Total & Percentage \\
\hline Absent & 2.5 & 0.1 & 3.9 & 6.5 & 21 \\
Low & 0.1 & 0.0 & 3.0 & 3.1 & 10 \\
Medium & 3.9 & 0.7 & 10.6 & 15.2 & 49 \\
High & 0.4 & 0.7 & 4.2 & 5.3 & 17 \\
Very high & 0.0 & 0.1 & 1.1 & 1.2 & 4 \\
\hline Total & 6.9 & 1.6 & 22.8 & 31.3 & \\
Percentage & 22 & 5 & 73 & & \\
\hline
\end{tabular}

For snags, there are two possibilities for scaling volume. If the snags are not broken, as the NFI has data on living tree volumes and considering that the scaled volume is the same between dead trees and living trees (Bruciamacchie, 2005), specific single-entry volume tables are calculated by species with an equation in the form of:

$$
V=a D B H^{2}+b D B H+c
$$

$V=$ snag volume,

$D B H=$ Diameter breast height.

For snags broken at a certain height, $D B H$ and the height of the broken point are measured, and a double-entry volume table is used to calculate the volume.

$$
V=H^{1.2} b D B H^{1.8}+c
$$

$V=$ broken snag volume,

$H=$ snag height,

$D B H=$ Diameter breast height.

For LIS, De Vries' formula (De Vries, 1986) was used, estimating $\log$ volume in $\mathrm{m}^{3} \mathrm{ha}^{-1}$. This formula requires only the length of the transect $(L)$ and the log diameter $(d)$ at the point of intersection.

$$
V=\frac{\pi^{2} \sum d^{2}}{8 L}
$$

$V=$ volume per hectare of CWD,

$d=\log$ diameter at the point of intersection of the transect perpendicular to the axis of the log,

$L=$ length of the transect.

\section{RESULTS}

Taking FAS as a basis, it is useful, for merely illustrative purposes, to see CWD volume at a minimum diameter of $7 \mathrm{~cm}$. For the range of plots measured, the minimum volume calculated is $0.3 \mathrm{~m}^{3} \mathrm{ha}^{-1}$ and the maximum is $93.1 \mathrm{~m}^{3} \mathrm{ha}^{-1}$ for an average of $31.3 \mathrm{~m}^{3} \mathrm{ha}^{-1}$ with $73 \% \mathrm{CWD}, 22 \%$ snags and $5 \%$ stumps (Tab. III). The plot with $0.3 \mathrm{~m}^{3} \mathrm{ha}^{-1}$ is a grazed oak stand with an extremely low tree density. The plot with the maximum volume has a lot of large wood maritime pine windthrows. These values should not be used as references but simply show that the sampling is performed under a range of conditions (Tabs. IV and V) and that CWD deadwood is the largest component of deadwood. They also vary depending on the method used.

The distribution by decay class shows that all the classes are represented, with the medium class being the majority, with $49 \%$, followed by the absent and high classes, with $21 \%$ and $17 \%$. The low and very high classes are very rare, with $10 \%$ and $4 \%$, respectively.

\subsection{Comparison of results using the various methods}

Let us now look at the difference between FAS on the 9-mradius plot and the 100-m transect overlaid on the plot with the same $7 \mathrm{~cm}$ of minimum diameter for lying deadwood. Only 29 samples can be compared since the understorey on two plots was too dense to measure CWD on the fixed-area plot without spending an extensive amount of time. FAS gives a mean volume of $22.87 \mathrm{~m}^{3} \mathrm{ha}^{-1}$ while LIS gives $25.96 \mathrm{~m}^{3} \mathrm{ha}^{-1}$. A non-parametric Wilcoxon's test for paired data was performed (samples are not normally distributed, the ShapiroWilk normality test gives a probability of $p=0.00022$ ). The comparison of the mean value pairs shows they are not significantly different for each method $(V=220, p=0.96)$.

\subsection{Choosing thresholds}

\subsubsection{Minimum diameter}

One approach involves comparing the number of deadwood pieces and the deadwood volume (Fig. 3) calculated by diameter class with the LIS method over $100 \mathrm{~m}$. This shows that as the diameter of the lying deadwood increases, the number of deadwood pieces decreases much faster than CWD volume. One other result is that pieces measuring less than or equal to $6 \mathrm{~cm}$ represent $25 \%$ of deadwood volume.

CWD pieces were assessed, starting at $0.5 \mathrm{~cm}$ for part of the transect section; it is possible to put together a graph (Fig. 4) showing the loss of deadwood volume when the minimum diameter increases. This graph shows that a minimum diameter of $7 \mathrm{~cm}$ would neglect about $40 \%$ of deadwood volume. If this is increased to $20 \mathrm{~cm}, 78 \%$ of the deadwood will not be inventoried. Figures 3 and 4 show that the number of small diameter pieces is extremely high and represents a considerable part of the deadwood volume. Assessing small diameters is much more time-consuming, as was presented above.

\subsubsection{Transect length}

The precision of the results on a plot scale can be deduced from the intra-plot variability using the mean coefficient of variation $(\mathrm{CV})$. With the sectioned transects, it is possible to 
Table IV. Distribution of the sampled plots by forest structure and composition and compared with France's national surface percentage and $\chi^{2}$ test results. The main structure type in the sampling is high forest and the main composition type is broadleaved. The structure and composition distributions of the sampling are statistically similar to France's distribution.

\begin{tabular}{|c|c|c|c|c|c|c|}
\hline Structure & High forest & Coppice with reserves & Coppice & Total & $\chi^{2}$ & $p$ \\
\hline Number of plots & 20 & 5 & 6 & 31 & & \\
\hline Percentage of plots & 65 & 16 & 19 & 100 & 2.50 & 0.29 \\
\hline Percentage France & 55 & 29 & 16 & 100 & & \\
\hline Composition & Broadleaved & Coniferous & Mixed & Total & $\chi^{2}$ & $p$ \\
\hline Number of plots & 19 & 7 & 5 & 31 & & \\
\hline Percentage of plots & 61 & 23 & 16 & 100 & 0.48 & 0.79 \\
\hline Percentage France & 58 & 28 & 13 & 100 & & \\
\hline
\end{tabular}

Table V. Mean time in minutes required to assess the various deadwood components using the various methods. Time efficiency of FAS seems low for CWD compared with LIS. Average assessment time of stumps and snags is high in regard to the proportion of deadwood volume that they represent.

\begin{tabular}{lcccc}
\hline $\begin{array}{l}\text { Deadwood } \\
\text { component }\end{array}$ & Method & $\begin{array}{c}\text { Radius } \\
\text { or length }\end{array}$ & $\begin{array}{c}\text { Min. } \\
\text { diameter }\end{array}$ & Time (min) \\
\hline Stumps & FAS & $9 \mathrm{~m}$ & $9.5 \mathrm{~cm}$ & 5.7 \\
Snags & FAS & $6,9,15 \mathrm{~m}$ & $0 \mathrm{~cm}$ & 8.6 \\
CWD & FAS & $9 \mathrm{~m}$ & $7 \mathrm{~cm}$ & 17.9 \\
CWD & LIS & $36 \mathrm{~m}$ & $4.5 \mathrm{~cm}$ & 8.6 \\
\hline
\end{tabular}

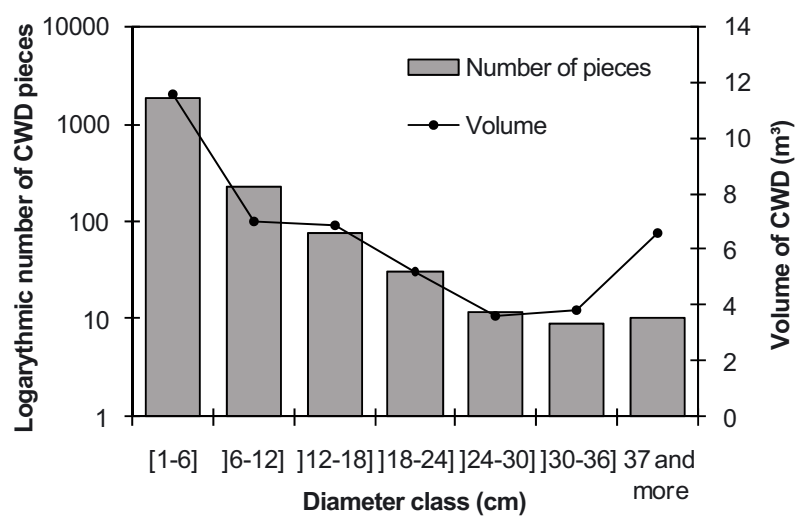

Figure 3. Distribution of the logarithmic number of CWD pieces (left axis) and CWD volume in cubic meters (right axis) by diameter class with the 100-m LIS method. As the diameter class increases the number of CWD pieces decreases much faster than the volume of deadwood.

randomly recreate transects having defined lengths by combining the sections. The sections of 3, 6 and $10 \mathrm{~m}$ were used to generate transect lengths from $3 \mathrm{~m}$ to $100 \mathrm{~m}$ with random sampling without replacement, which gave $2^{16}-1=65535$ possibilities per plot for a total of 2031585 generated transects. The $\mathrm{CV}$ is calculated for each length. The variance is not calculated using the finite population variance formula. Because of the resampling, this calculation could not be used since it does not compare entirely independent transect sections. Using Geary's

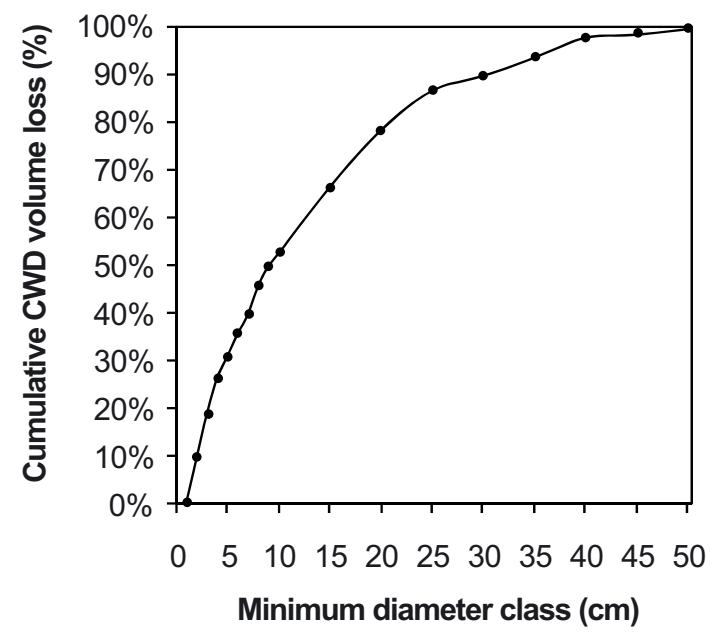

Figure 4. Cumulative loss of volume proportion of CWD when the minimum diameter increases using the 100 -m LIS method. Increasing the minimum diameter to $7 \mathrm{~cm}$ would neglect $40 \%$ of CWD volume. If this is increased to $20 \mathrm{~cm}, 78 \%$ of the deadwood will not be inventoried.

index (Chessel and Thioulouse, 2003) makes it possible to compare totally independent transects two by two without repeated sections. This variance calculation has a drawback: the maximum length variance calculation is reduced from 100 to $50 \mathrm{~m}$ because the transect samples are compared by pairs. The variance is transformed into the $\mathrm{CV}$.

Expression of the variance with Geary's index:

$$
W_{i} W_{j} \sum_{i=1}^{n} \sum_{j=1}^{n}\left(x_{i}-x_{j}\right)^{2}=2 \text { Var }
$$

Variance:

$$
\operatorname{Var}=\frac{1}{2} \sum_{i=1}^{n} \sum_{j=1}^{n}\left(x_{i}-x_{j}\right)^{2}
$$

where $i$ and $j$ are paired combinations, $\mathrm{n}$ is the number of pairs that can be generated, and $W i$ and $W j$, the weight of each element of a pair, are here considered equal to 1 . 


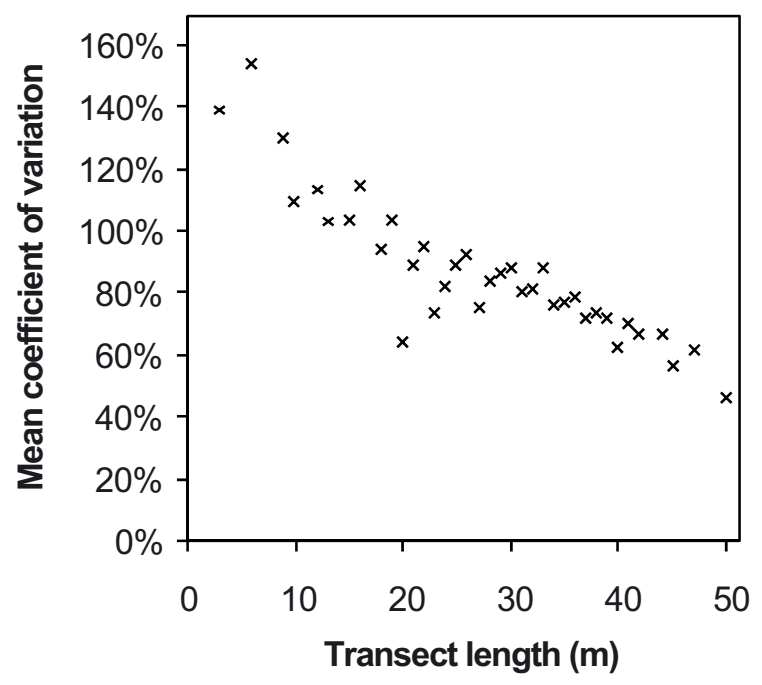

Figure 5. Intra-plot variability expressed with the mean coefficient of variation by transect length for CWD using simulated transect length. $\mathrm{CV}$ is not yet stabilized and can still decrease after $50 \mathrm{~m}$. Difference in CVs having similar lengths is due to a different number of combinations per length: 6 combinations for $20 \mathrm{~m}$ and 331 for $21 \mathrm{~m}$.

Figure 5 shows the evolution of the CV (calculated with variance equation (6) and the mean values for each length) when the transect length increases.

\subsubsection{Number of plots at the national level}

The distribution of the structure and composition per plot was reproduced to have an overall sample of the main French forest types, in order to be able to apply it at the national level. The results of the $\chi^{2}$ distribution comparison test show that the samples statistically have the same distribution as France's structure and composition (Tab. IV).

Considering that CWD represents the most significant deadwood component in terms of volume in the forest $(73 \%)$ and that our sampling, given its main structure type and composition, is statistically representative (Tab. IV) of what could be expected at the national level, changes in standard deviation can be simulated, depending on the plot number and the transect length. This was done using equation (7), where $\mathrm{n}$ is $31, \sigma$ is the corresponding calculated standard deviation for a defined transect length, and $\sigma^{\prime}$ is the simulated standard deviation of a sample of $n^{\prime}$.

$$
\sigma^{\prime}=\sigma \sqrt{\frac{n-1}{n^{\prime}-1}} .
$$

The French NFI plot grid is always systematic. For example, every year an average of 7000 plots are assessed; if taking a measurement is too expensive, an inventory can be conducted on a still systematic sub-sample of 3500 , and so on for smaller sub-samples. The simulation of the volume standard deviation is calculated for seven levels of n' sub-samples

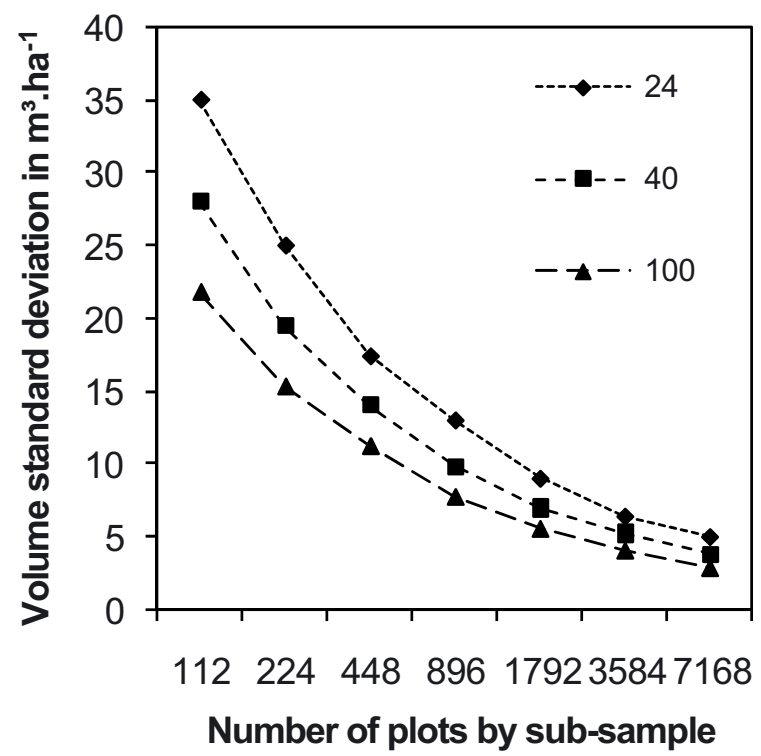

Figure 6. Simulation of changes in the CWD volume standard deviation when the number of plots per sub-sample increases for 24-m, 40-m and 100-m transect lengths. It shows that more than the length of the transect, the number of plots plays the main role in decreasing standard deviation.

and repeated for 24-, 40- and 100-m transect lengths (Fig. 6). To obtain an accurate estimate at the national level, assessing a large amount of plots seems more necessary than having longer transects.

\subsection{Assessing efficiency}

The results in Table $\mathrm{V}$ are expressed on a comparable scale as far as possible. It took $5.7 \mathrm{~min}$ to inventory the stumps on a 9-m-radius plot, 8.6 min for snags for 6-, 9- and 15-m-radius plots, $17.9 \mathrm{~min}$ for CWD for a 9-m-radius plot and $8.6 \mathrm{~min}$ with a 36-m-long transect.

A great deal of time is required to measure stumps and CWD with the fixed-area plot because stumps and pieces can be hidden by the understorey and careful searching is necessary throughout the plot area. Dense understorey can require a large amount of time. We had two plots where we decided to cancel the CWD assessment with FAS because it would have taken much too long to clean up and prospect all over the plot.

Looking in detail at the CWD using the LIS method, measurement time can be separated into the installation of the transect and the measurement for a minimum diameter. Using our recordings, it is possible to calculate speeds for each step; the results are shown in Table VI. The installation is considered proportional to the transect length, with a speed of $7.2 \mathrm{~s} \mathrm{~m}^{-1}$. For the measurement, the resulting speed is $40 \mathrm{~s} \mathrm{~m}^{-1}$ for $0.5 \mathrm{~cm}$ and $11 \mathrm{~s} \mathrm{~m}^{-1}$ for 4.5 . Using these speeds, it is possible to calculate the time for every transect length. Decreasing the minimum diameter would require much more time. 
Table VI. Synthesis of the speed assessment in seconds per meter for CWD along a transect with 0.5 and $4.5 \mathrm{~cm}$ minimum diameters. The main impact on assessment speed is the minimum diameter.

\begin{tabular}{lc}
\hline Step & Speed s m$^{-1}$ \\
\hline Installation of the transect & 7.2 \\
Measurement from $0.5 \mathrm{~cm}$ & 40 \\
Measurement from $4.5 \mathrm{~cm}$ & 11 \\
\hline
\end{tabular}

\section{DISCUSSION}

The results in Table III show that in this sampling, CWD (73\%) and snags (22\%) were the main components of deadwood volume. Stumps represented only $5 \%$ of volume with $25 \%$ of assessment time. Interest in them seems to be limited in the literature, especially in the forest types available in France (Humphrey et al., 2004). If stumps are inventoried, the size of the FAS should be reduced.

FAS is a good method for assessing snags. Currently, at the French NFI, snags (dead for less than 5 years) are assessed in the 15-m-radius plot. Since snags are rare and their measurement is separated from the dendrometric inventory, field crews often fail to measure some of them. Their volume is probably underestimated. Snags should be included in the dendrometric inventory where living trees are recorded, as tested in this study.

The main objective of the study was to compare two common CWD assessment methods: FAS and LIS. Mean volumes per hectare statistically had the same results. FAS was found to be much more time-consuming (Woldendorp et al., 2004) (Tab. V), especially when understorey was dense.

FAS has a higher tendency for non-detection than LIS (Kaiser, 1983). While LIS is commonly used as an unbiased reference (Woldendorp et al., 2004), one study showed that there is a slight bias of non-detection for LIS, especially when CWD density is high (Ringvall and Ståhl, 1999). This study did not test this effect but when inventorying CWD, the field crew had the impression that the risk of omitting pieces was higher with FAS.

For Bruciamacchie (Bruciamacchie, 2005), the best compromise for assessing CWD would be a mix of methodologies: FAS for CWD over $30 \mathrm{~cm}$ and LIS for 5- to 30-cm CWD. Various transect shapes have been tested in the literature such as polygons, triangles, fans, "Y"s and "L"s. In terms of accuracy, the superiority of one design over another is not clear (Affleck et al., 2005). If pieces are randomly oriented, setting up a simple design is quicker to implement with similar results (Kaiser, 1983). If pieces are positioned in one direction, the piece orientation bias can be reduced by running two or more transects out from the same plot (Van Wagner, 1968).

For the French NFI, the current minimum diameter is $7.5 \mathrm{~cm}$ (for snags). Figure 3 showed that small-diameter CWD represent a large part of total CWD volume. Harmonization between inventories is easier if the minimum common diameter is low (Humphrey et al., 2004). A minimum diameter approaching 0 should be used to assess all woody debris, as done by the USDA Forest services or the Canadian NFI, even if CWD as a potential indicator for saproxylic and epixylic species seems interesting in most French forest types from a minimum diameter of $20 \mathrm{~cm}$ (Humphrey et al., 2004). As large CWD's role in biodiversity is well known, FWD plays an important role in biodiversity as well. For the same volume, FWD has a higher species richness compared with CWD. If looking specifically at fungi, FWD offers a larger surface area per volume, which means more space for fungi than larger CWD. In addition to that, FWD would present more separate units at equal volume than larger CWD, and represent more individual possible fungi infection (Heilmann-Clausen and Christensen, 2004; Kruys and Jonsson, 1999). In managed forest where large CWD is rare (Brin et al., 2008), FWD should not be neglected (Kruys and Jonsson, 1999). However, tallying FWD is highly time-consuming. As applied in this test and as implemented by the USDA Forest Service or the Canadian NFI, FWD is tallied on a small section of the CWD transect. Otherwise it would be impractical for field crews to measure the diameters of hundreds of FWD on the whole transect.

Figure 5, presenting changes in the $\mathrm{CV}$ when transect lengths increase, shows that on the plot scale, the CV gradually declined until $50 \mathrm{~m}$ without stabilizing. Woldendorp (Woldendorp et al., 2004) has a greater CV reduction when transect lengths increase from 10 to $40 \mathrm{~m}$ than from 40 to $80 \mathrm{~m}$. Unfortunately, when using Geary's index, it was not possible to simulate over $50 \mathrm{~m}$ to observe a beginning of stabilization. In general, the longer the transect, the smaller the error of the volume estimation (Bruciamacchie, 2005; De Vries, 1986; Marshall et al., 2000; Woldendorp et al., 2004). The various NFIs that use LIS show that one standard transect length has not been adopted (Woodall and Williams, 2005).

Figure 6 shows that the effect of the increase in precision was higher with the increment in the plot number than the increment in the length. The French NFI can assess an average of 7000 plots a year and can expect a standard error under 6 regardless of the length ( 24 to $100 \mathrm{~m}$ ). The low precision on a plot scale is offset by the large number of plots assessed.

For LIS, this study proposes assessment time functions depending on the length of the transects in Table VI. Bölhl (Bölhl, 2007) gives a required assessment time between 5 and $6 \mathrm{~min}$ for two locations for a $30-\mathrm{m}$ transect length and $7 \mathrm{~cm}$ as minimum diameter. For the same length and with $4.5 \mathrm{~cm}$ as minimum diameter, the function gave a time of $9.1 \mathrm{~min}$. This showed that the function seemed comparable with a smaller minimum diameter. It can be used to estimate the expected time for a chosen length.

In addition to precision, there are biases related to the methodology that should be taken into account (Bölhl, 2007; Wadell, 2002). The LIS formula (4) proposed to calculate CWD volume assumes that a piece at the point of intersection of the transect is always circular. To limit the effect of this imprecision, it is better to measure two orthogonal diameters and record the mean diameter. Another hypothesis is that all wood pieces lie horizontally on the ground. In fact, it is common to have pieces with tilt. The bias can be significant (Bölhl, 2007; Brown and Roussopoulos, 1974). One way of reducing this bias is to measure the tilt of each piece, as practiced by the Swiss NFI (Bölhl, 2007). 


\section{CONCLUSION}

In this study, practical tools are developed to give methodological guidelines in terms of accuracy and cost. Even if an inventory is always a compromise between the precision and the cost of the measurement, it seems that the French NFI should choose LIS for CWD and FAS for snags and stumps. LIS is quicker and more regular in the assessment time. It is easy to set up. It has few biases if the protocol has previously taken them into account. On the one hand, a low minimum diameter, a long transect and a large number of plots are required to have higher accuracy. But on the other hand, it greatly increases the cost of the assessment. A good compromise would be to have a moderately long transect ( 30 to $50 \mathrm{~m}$ ) with one section for FWD and the other section only for CWD with higher diameters $(7 \mathrm{~cm})$. The transect design should be simple, using a "L" or a fan, for example, with a random orientation. The imprecision due to the moderately long transect would be offset by a large number of assessed plots (7 000).

This preliminary study will be used by the French NFI to develop an efficient deadwood inventory compatible with other countries and international processes.

This study focuses on volume per-unit-area. However, deadwood may also be expressed in terms of piece distribution, surface area, CWD cover, number of pieces, holes and hollow trees. These indicators are more specific on one role of deadwood or one group of species. Deadwood volume is an integrated indicator that can be enriched with such parameters deducted from raw data or supplementary measurements.

Deadwood is part of down woody materials such as litter, slash piles, duff, fuelbed, live/dead shrubs and live/dead herbs. The next step will be to develop inventories for all these components to have a complete overview of woody material. The USDA Forest Service already carries out inventories of down woody materials.

Acknowledgements: This study would never have been initiated without the previous work done by the FORSEE and BIOSOIL projects. The authors thank all the members of the French national forest inventory who participated in the study.

\section{REFERENCES}

Affleck D.L.R., Gregoire T.G., and Valentine H.T., 2005. Edge effects in line intersect sampling with segmented transects. J. Agr. Biol. Env. Stat. 10: 460-477.

Böhl J., 2007. Deadwood volume assessment in the third Swiss National Forest Inventory: methods and first results. Eur. J. For. Res. 126: 449-457.

Brin A., Meredieu C., Piou D., Brustel H., and Jactel H., 2008. Changes in quantitative patterns of dead wood in maritime pine plantations over time. For. Ecol. Manage. 256: 913-921.

Brown J.K. and Roussopoulos PJ., 1974. Eliminating biases in the planar intersect method for estimating volumes of small fuels. For. Sci. 20: $350-356$.

Bruciamacchie M., 2005. Méthode d'échantillonnage du bois mort, Bois mort à cavités, une clé pour des forêts vivantes, Lavoisier, Paris, pp. $228-235$.
Bull E.L., Parks C.G., and Torgersen T.R., 1997. Trees and logs important to wildlife in the Interior Columbia River Basin. Gen. Tech. Rep. PNW-GTR-391. Portland, OR: U.S. Department of Agriculture, Forest Service, Pacific Northwest Research Station, 55 p.

Caza C.L., 1993. Woody debris in the forests of British Columbia: a review of literature and current research, British Columbia, Ministry of Forests, Research Branch, Victoria, 99 p.

Chessel D. and Thioulouse J., 2003. Analyse de données spatialisées, Fiche de biostatistique, Biométrie et Biologie Evolutive, Université Lyon 1, $30 \mathrm{p}$.

De Vries P.G., 1986. Sampling theory for forest inventory. A teachyourself course, Springer-Verlag, Berlin, 420 p.

Delisle G.P., Woodard P.M., Titus S.J., and Johnson A.F., 1988. Sample size and variability of fuel weight estimates in natural stands of lodgepole pine. Can. J. For. Res. 18: 649-652.

Feller M.C., 2003. Coarse woody debris in the old-growth forests of British Columbia, Environ. Rev. 11: 135-157.

Filho A.F., Machado S.A., and Carneiro M.R.A., 2000. Testing accuracy of $\log$ volume calculation procedures against water displacement techniques (xylometer). Can. J. For. Res. 30: 990-997.

Gove J.H., Ringvall A., Stahl G., and Ducey M.J., 1999. Point relascope sampling of downed coarse woody debris. Can. J. For. Res. 29: $1718-1726$.

Harmon M.E., Franklin J.K., Swanson F.J., Sollins P., Gregory S.V., Lattin S.D., et al., 1986. Ecology of coarse woody debris in temperate ecosystems. Adv. Ecol. Res. 15: 133-302.

Harmon M.E. and Sexton J., 1996. Guidelines for measurements for of woody detritus in forest ecosystems. Publication No. 20, U.S. LTER Network, College of Forest Resources, University of Washington, Seattle, Wa. 73 p.

Heilmann-Clausen J. and Christensen M., 2004. Does size matter? On the importance of various dead wood fractions for fungal diversity in Danish beech forests, For. Ecol. Manage. 201: 105-117.

Humphrey J.W., Sippola A.L., Lempérière G., and Dodelin B., 2004. Deadwood as an indicator of biodiversity in European forests: from theory to operational guidance. In: Marchetti M. (Ed.), Monitoring and indicators of forest biodiversity in Europe - from ideas to operationality, EFI Proceedings 51: 193-206.

Jordan G.J., Ducey M.J., and Gove J.H., 2004. Comparing line-intersect, fixed-area, and point relascope sampling for dead and downed coarse woody material in a managed northern hardwood forest. Can. J. For. Res. 34: 1766-1775.

Kaiser L., 1983. Unbiased estimation in line-intersect sampling, Biometrics 39: 965-976.

Kruys N. and Jonsson B.G., 1999. Fine woody debris is important for species richness on logs in managed boreal spruce forests of northern Sweden. Can. J. For. Res. 29: 1295-1299.

Marshall P.L., davis G., and Le May V.M., 2000. Using line intersect sampling for coarse woody debris. For. Res. Tech. Rep. 37 p.

McKenzie N., Ryan P., Fogarty P., and Wood J., 2000. Sampling, Measurement and Analytical Protocols for Carbon Estimation in Soil, Litter and Coarse Woody Debris. National Carbon Accounting System, Technical Report No. 14, Australian Greenhouse Office, Canberra, $52 \mathrm{p}$.

MCPFE, 2003. Background information for improved pan-european indicators for sustainable forest management, MCPFE, Vienna, Austria, $46 \mathrm{p}$.

IPCC, 2003. Good Practice Guidance for Land Use, Land-Use Change and Forestry. In: Penman J., Gytarsky M., Hiraishi T., Krug T., Kruger D., Pipatti R., Buendia L., Miwa K., Ngara T., Tanabe K., and Wagner F. (Eds.), IPCC/OECD/IEA/IGES, Hayama, Japan. 
Ringvall A. and Ståhl G., 1999. Field aspects of line intersect sampling for assessing coarse woody debris. For. Ecol. Manage.119: 163-170.

Ståhl G., 1997.Transect relascope sampling for assessing coarse woody debris: the case of a $\pi / 2$ relascope angle. Scand. J. For. Res. 12: $375-381$

Stevens V., 1997. The Ecological role of coarse woody debris, an overview of the ecological importance of CWD in BC Forests, Working paper 30, British Columbia, Ministry of Forests Research Program, Canada, $32 \mathrm{p}$.

Stokland J.N., Tomter S.M., and Söderberg G.U., 2004. Development of dead wood indicators for biodiversity monitoring; experiences from Scandinavia. In: Marchetti M. (Ed.), Monitoring and indicators of forest biodiversity in Europe - from ideas to operationality. EFI Proceedings 51: 207-226.
Van Wagner C.E., 1968. The line intercept method in forest fuel sampling. For. Sci. 14: 20-26.

Wadell K.L., 2002. Sampling coarse woody debris for multiple attributes in extensive resource inventories. Ecol. Indic. 1: 139-153.

Warren W.G. and Olsen P.F., 1964. A line transect technique for assessing logging waste. For. Sci. 10: 267-276.

Woldendorp G., Keenan R.J., Barry S., and Spencer R.D., 2004. Analysis of sampling methods for coarse woody debris. For. Ecol. Manage. 198: 133-148.

Woodall C. and Williams M., 2005. Sampling protocol, estimation, and analysis procedures for the down woody materials indicator of the FIA program, Gen. Tech. Rep. NC-256. St. Paul, MN: U.S. Department of Agriculture, Forest Service, North Central Research Station, $47 \mathrm{p}$. 